\title{
A reserva de vagas para negros nas universidade brasileiras*
}

\author{
YVONNE MAGgIE ePETER FRY
}

\section{Introdução}

C

O M O OBSERVOU M ichel Agier (2002), entrea promulgação da Constituição brasileira de 1988 e al II Conferência M undial das N ações U nidas de Combate ao Racismo, D iscriminação Racial, Xenofobia e Intolerância Correlata, que teve lugar em D urban, na África do Sul, em 2001, a postura do governo do Brasil perante a questão racial mudou radicalmente. A Constituição de 1988 reconhece e condena o racismo, punindo-o como crime inafiançável. N esse sentido, mantém a longa tradição formal republicana brasileira do a-racismo e do anti-racismo. Para a Conferência de D urban, a delegação oficial brasileira encaminhou uma proposta que rompeu com esta tradição, propondo "ações afirmativas" em favor da "população afro-descendente", entre elas o reconhecimento oficial da legitimidade de reparações para com a escravidão e cotas para negros nas universidades públicas. Enquanto isso, o M inistro da Reforma Agrária anunciou que, doravante, vinte por cento das vagas no seu ministério seriam destinados a negros. A idéia logo se espalhou pela $E$ splanada dos $M$ inistérios ( o $M$ inistério de Educação sendo exceção) e, em dezembro, o presidente da República estendeu o princípio para o funcionalismo público em geral. N o mesmo mês, a Assembléia dos $D$ eputados do E stado do Rio de J aneiro aprovou por aclamação, e, portanto, sem debate, uma lei que "institui cota de até quarenta por cento para as populações negra e parda no acesso à U niversidade do Estado do Rio de J aneiro eà U niversidade Estadual do N orte Fluminense" (L ei no 3708, de 9 de novembro de 2001).

Talvez val ha a pena explicitar a natureza dessa mudança. $\mathrm{Na}$ C onstituição de 1988, as palavras "raça" e "racismo" aparecem três vezes, cada uma delas no sentido de repudiar "raça" como critério de distinção. 0 inciso IV do artigo 3 reza que, entre os objetivos fundamentais da R epública Federativa do Brasil, está a promoção do "bem de todos, sem preconceitos de origem, raça, sexo, cor, idade e quaisquer outras formas de discriminação". O inciso VIII do artigo 4 afirma que a República Federativa do Brasil rege-se nas suas relações internacionais pelo "repúdio ao terrorismo e ao racismo". Finalmente, o inciso XLII do artigo 5 define a prática do racismo como "crime inafiançável e imprescritível, sujeito à pena de reclusão, nos termos da lei".

* Texto publicado originalmente em Enfoques (Revista Eletrônica), Rio de Janeiro, vol. 1, no 1, 2002, pp. 93-117. 
As medidas pós-Durban, ao proporem ações afirmativas em prol da "população negra", rompem não só com o a-racismo e o anti-racismo tradicionais, mas também com a forte ideologia que define o Brasil como país da mistura, ou, como preferia Gilberto Freire, do hibridismo. Ações afirmativas implicam, evidentemente, imaginar o Brasil composto não de infinitas misturas, mas de grupos estanques: os que têm e os que não têm direito à ação afirmativa, no caso em questão, "negros" e "brancos"...

Em entrevista recente, o economista Ricardo H enriques, que tem sido muito ativo no apoio às novas medidas, afirmou que no Brasil "é preciso tratar desigualmente os desiguais":

$\mathrm{N}$ osso desafio é romper com a matriz republicana francesa. Todos nós fomos culturalmente educados e a grande maioria estudou numa base dessa grande matriz francesa universalista, que acha que o imperativo da igualdade é a melhor matriz para fazer qualquer intervenção, tratando todos por iguais. Esta é a estratégia mais cínica de lidar com o problema. (H enriques, 2002)

Sem querermos entrar numa discussão sobre a distribuição de cinismo no B rasil, parece claro que o cidadão brasileiro, pelo menos perante às universidades e à função pública, não poderá mais se identificar com o M acunaíma do modernismo brasileiro; agora ele terá que pertencer a uma "raça" ou a outra.

Anos atrás, um de nós sugeriu que no Brasil preferimos pontes a margens (M aggie, 1992). M ais recentemente, outro, ao observar as dificuldades enfrentadas pelos projetos de lei que propunham cotas para negros nas universidades e no funcionalismo público - e a reticência a cotas manifesta num congresso internacional que teve lugar para discutir o assunto em 1996 (Souza, 1997), no qual o próprio presidente da República exortou os presentes a exercerem sua criatividade para desenvolver políticas apropriadas ao caso brasileiro, evitando a adoção de cópias de políticas de outras sociedades -, chegou a ponto de afirmar que

[... ] cotas são nauseabun das para muitos não apenas porque parecem contradizer o ideal da "democracia racial" e democracia liberal tout court, mas também porque parecem ameaçar a idéia modernista da antropofagia. É como que se o Brasil comesse a ação afirmativa formalizada, outras comidas que tanto gosta tornar-se-iam crescentemente desagradáveis, não menos a mistura em si. (Fry, 2000, p. 83).

E videntemente, então, a repentina adoção de cotas como política de Estado nos surpreendeu, e muito. Estávamos errados? E se estávamos, por quê? N este ensaio bastante experimental argumentaremos que estávamos errados em dois pontos: 1) não imaginávamos que as cotas seriam virtualmente decretadas, e mesmo se tivéssemos imaginado que isso pudesse acontecer, provavelmente não teríamos antecipado o extraordinário poder das decisões "de cima para baixo" nesse país que queríamos imaginar democrático; 2) subestimamostalvez 0 avanço em certas áreas-chave da substituição de um Brasil imaginado como composto 
de "raças misturadas" por um país de "raças distintas". O u seja, o nosso erro foi apostar que uma tradição "vencesse" a outra. Wishful thinking, muito provavelmente.

$\mathrm{N}$ ão houve debate público nem entre os representantes dos el eitores antes dos decretos ministeriais e da promulgação da lei de cotas no Rio de Janeiro. Antes da Conferência de D urban, o comitê nomeado pelo governo federal para preparar a posição do Brasil promoveu três seminários, em Belém, Salvador e São Paulo. M as poucos souberam ou participaram, além de ativistas negros ${ }^{1}$. 0 frágil debate começou, portanto, depois dos fatos consumados. 0 fato é que a falta de debate público impediu que se pudesse verificar se houve ou não uma mudança radical no Brasil como um todo. M esmo assim, as reações às medidas que apareceram na imprensa, que incluem alguns editoriais e artigos de historiadores, mas sobretudo cartas de leitores, avançam, na sua maioria, argumentos contra as medidas, assim sugerindo que os princípios a-racistas ainda vigoram no Brasil. Sem desmerecer a importância dos editoriais e artigos de intelectuais, consideraremos aqui apenas as cartas de leitores dirigidas ao jornal O G lobo durante os anos de 2001 e 2002, na suposição de que representem opiniões que extrapolam os muros das universidades. São os "nativos", que, na tradição da nossa antropologia, devem ser levados a sério.

\section{As cartas dos leitores}

O que mais chama a nossa atenção nas cartas é a coerência dos argumentos. O s leitores que as escreveram sugerem que a introdução de cotas raciais talvez não alcance o que pretende e terá efeitos que irão muito além das finalidades explícitas nos pronunciamentos dos governantes, em particular uma bipolarização racial e um aumento de tensão inter-racial, sobretudo nas camadas menos favorecidos da população. Todos aqueles que são a favor ou contra reconhecem que as cotas raciais representam uma ruptura com a tradição a-racista brasileira.

A questão da constitucionalidade das cotas é um assunto regularmente levantado pelos missivistas:

A Constituição diz que todos são iguais perante a lei [escreve J oão Carlos Rodrigues], portanto, são ilegais a aposentadoria feminina com cinco anos menos que a dos homens; a preferência pelos idosos em ações na Justiça; e as cotas raciais no ensino e no serviço público. C reio que basta uma interpelação ao ST F

[Supremo Tribunal Federal] para derrubar tudo isso. M elhor oportunidade para todos, e não apenas para alguns, num ano eleitoral. ( 0 Globo, Cartas dos L eitores, 15 maio 2002)

“Está na hora de os políticos lerem a C onstituição. N ão à discriminação; não a cotas para quem quer que seja", é a opinião de Vitor Sawczuk (O Globo, Cartas dos L eitores, 15 maio 2002).

A constitucionalidade ou não das cotas só será definida quando e se al guém que se sinta prejudicado entre com ação na Justiça, como fez o branco Alan Bakke nos Estados U nidos, que, não conseguindo entrar na Faculdade de 
M edicina Davis, da U niversidade da Califórnia, questionou nos tribunais a legalidade da política de admissões que reservou dezesseis vagas para candidatos negros. O caso chegou à Corte Suprema, onde Bakke saiu vitorioso, e as cotas foram declaradas inconstitucionais (Thomas, 1999). O snossos leitores não podem saber, de fato, se as cotas serão ou não julgadas inconstitucionais. 0 que eles estão expressando é o sentimento de que as cotas contrariam o a-racismo que associam ao Brasil e à sua C arta M agna.

U m outro argumento recorrente é aquele que diz que discriminar, mesmo que positivamente, é uma forma de racismo e corre contra a "tradição brasileira". Q uatro exemplos:

Tanto fizeram que o Brasil, país de muitas raças e misturas, forte pela sua diversidade, fraco pela sua distribuição de renda, agora é um país oficialmente racista. Com a criação de cotas para negros no serviço público federal institui-se oficialmente o apartheid brasileiro. (José Eduardo Loureiro.O Globo, Cartas dos L eitores, 10 nov. 2001)

Sou negra e, como tal, manifesto meu protesto contra o projeto de lei que estabelece cotas para minha raça para vagas em universidades e no serviço público. E ste projeto, na verdade, é um retrocesso do processo de integração dos negros à sociedade brasileira já que, através de uma segregação descabida, criará ressentimentos raciais, especialmente entre os mais jovens. ( $M$ aria Eudóxia de L ima Paes Leme. 0 Globo, Cartas dos Leitores, 21 abr. 2002)

Alerto aqueles que lêem em cada notícia, em entrelinhas imaginárias, a presença da segregação racial que nunca fez parte da nossa cultura: cuidado! 0 racismo está realmente presente quando se separa negros e brancos em percentuais e quantidades, e a cada passo aproximamo-nos do "Brasil branco" e do "Brasil negro". O Brasil, coração do mundo, pátria do evangelho para qualquer crença, tem de despertar para a beleza da miscigenação. N egros, brancos e todos os outros são filhos do mesmo D eus. É preciso lutar, unidos 100\%, por educação, saúde, moradia, alimentação, pelos por centos devidos a cada necessidade do homem, e bradar: "somos um povo bem colorido, brasileiros com muito orgulho". (Alice Regina de O rnellas. O Globo, Cartas dos Leitores, 11 dez. 2001)

A adoção de cursos especiais para negros seria o reconhecimento oficial de que existem raças no Brasil. I sso, num momento em que a genética acaba de provar que o conceito de raças não tem uma base científica. (H elen R umanjek. O Globo, Cartas dos L eitores, 29 ago. 2001)

N um ponto, pelo menos, não há antropólogo que possa discordar desses leitores: as "raças" de fato não existem naturalmente, e um sistema de cotas implica logicamente a criação de duas categorias "raciais": os que têm direito e os que não têm. Afinal, ou você tem direito à cota ou não tem! O sistema de cotas, então, representa, de certa forma, a "vitória" de uma taxonomia bipolar sobre a velha e tradicional taxonomia de muitas categorias. 
D ada a importância dessa mudança, segue agora uma pequena digressão sobre a política governamental acerca da classificação "racial" no Brasil nosúltimos anos. É preciso notar que as propostas levadas à Conferência de Durban e os pressupostos da política de cotas são rigorosamente consistentes com o ideário do governo federal desde 1995, quando o recém-eleito presidente Fernando $\mathrm{H}$ enrique Cardoso criou um Grupo de Trabal ho Interministerial com o objetivo de sugerir ações e políticas de valorização da população negra. No ano seguinte ele apresentou o seu programa de direitos humanos (Programa $\mathrm{N}$ acional de Direitos H umanos, 1996), que incluiu um capítulo específico dedicado à "população negra". E ste capítulo lista ações das mais tímidas às mais radicais. As primeiras sugerem a inclusão do quesito "cor" em todos os documentos oficiais, o estímulo da presença dos "grupos étnicos que compõem a nossa população" (Programa $\mathrm{N}$ acional deD ireitosH umanos, 1996), em propagandas institucionais contratadas pelo governo e apoio às "ações da iniciativa privada que realizem discriminação positiva". As mais radicais incluem o desenvolvimento de "ações afirmativas para o acesso dos negros aos cursos profissionalizantes, à universidade e às áreas detecnologia de ponta" ea intenção de "formular políticas compensatórias que promovam social e economicamente a comunidade negra", (Programa $\mathrm{N}$ acional de Direitos H umanos, 1996). Propõe também que o país abandone a sua secular taxonomia oficial de "pretos, pardos e brancos" para uma taxonomia bipolar ao "determinar ao IBGE a adoção do critério de se considerar os mulatos, os pardos e os pretos como integrantes do contingente da população negra" (Programa $\mathrm{N}$ acional deDireitos H umanos, 1996) (grifos nossos).

Esta última proposta, por mais inócua que possa parecer, é, pensamos, a mais radical de todas, pois representa uma quebra total em relação à antiga ideologia do Brasil racialmente misturado, o B rasil das infinitas gradações de cor, a favor de uma taxonomia congruente com as do resto do mundo, em particular a África do Sul e os Estados U nidos da América. M as essa maneira de ver o mundo não é compartilhada pelos nossos missivistas. Eles expressam dúvidas, inclusive, sobre a possibilidade efetiva de classificar os brasileiros em duas categorias estanques. Como diz, por exemplo, César Augusto N icodemus de Souza:

[... ] filho de família com raízes no Agreste pernambucano, numa região onde houve grande miscigenação, gostaria de saber até que ponto a tonalidade da pele de meus filhos e outras características serão consideradas para a aceitação deles na cota dos vinte por cento de negros que terão privilégio em universidades e concursos públicos. A cor de seus olhos e o tipo de cabelo também serão levados em consideração ou a padronização será mediante teste de DN A? Sei onde estão enterrados meu pai e avós, mas não saberia indicar outros locais onde colher $\mathrm{o}$ indispensável material para tal análise. $\mathrm{N}$ ão sei se $\mathrm{o}$ fato de ter casado com uma moça de pele clara e olhos azuis poderá vir a prejudicar meus filhos e netos, agora que as vagas nos concursos não serão mais preenchidas só pela competência. (O Globo, C artas dos L eitores, 21 abr. 2002). 


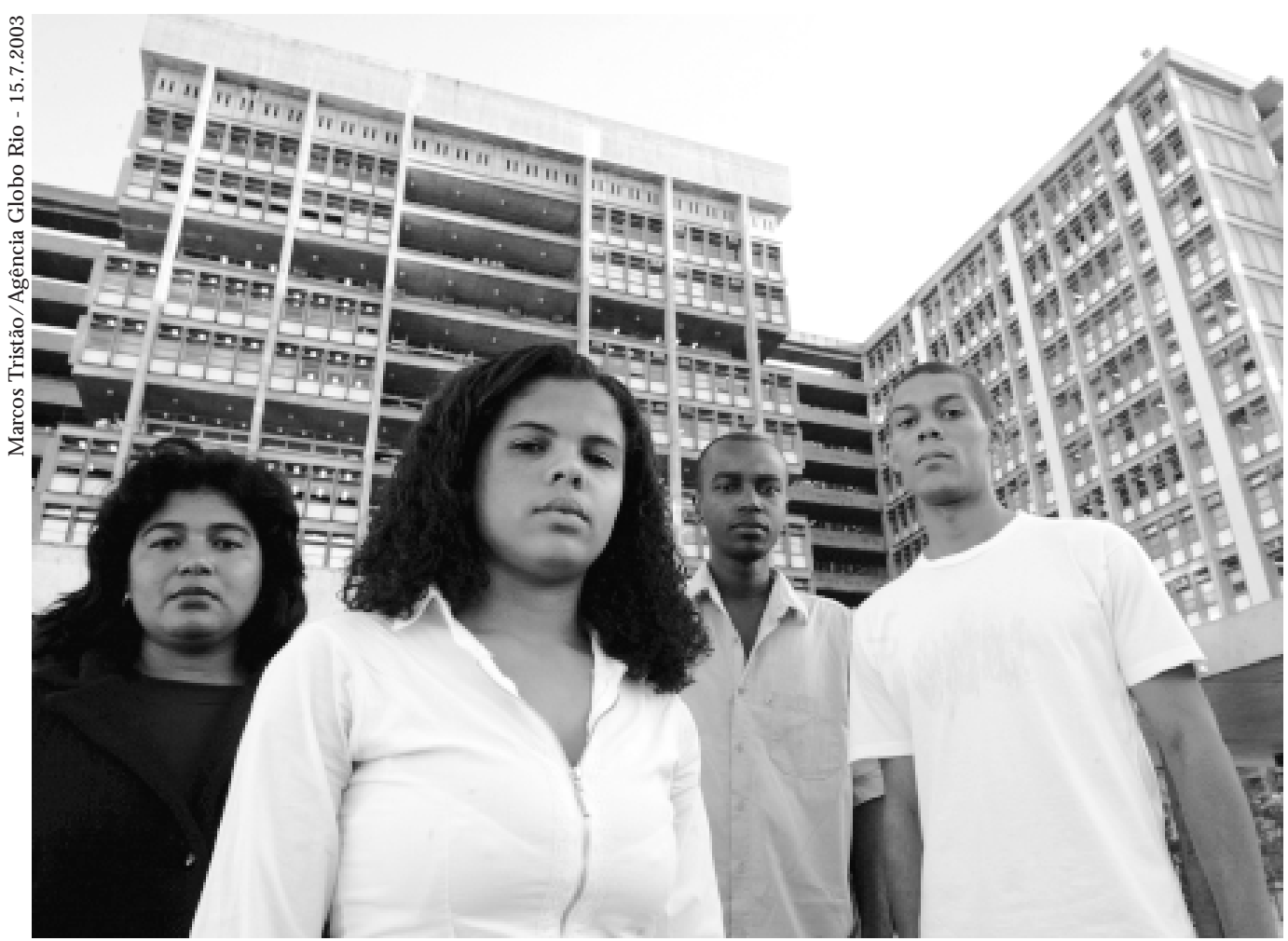

Falta de condi çõesfinancei rasfaz alunos negros da U FR J pensarem em abandonar curso.

O u, nas palavras de R enato Vasconcellos a propósito da criação de cursos pré-vestibulares para "negros": "G ostaria de perguntar ao ministro da E ducação como ele irá selecionar, num país como o nosso, em que a mistura racial é enorme, quem é negro ou branco." (O Globo, Cartas dos Leitores, 28 ago. 2001). O u, mesmo, M arco Fonseca:

Sou neto de uma negra, mas tenho pele branca. I sso me faz negro ou branco? Q uem terá o direito de me separar das minhas raízes, da minha cultura, ao dizer que, pela minha pele clara, eu não teria direito a uma vaga reservada aos negros? O Rio vai criar uma política de segregação racial, em que a condição social é menos importante que a cor da pele. (0 Globo, Cartas dos Leitores, 8 mar. 2002)

O s formuladores das leis estão cientes desse problema, tanto é que não definiram quem é branco ou quem é negro a partir de dados "objetivos", deixando a definição para quem se candidata, o que é chamado de autoclassificação. Resta saber se pensaram muito nas possíveis conseqüências sugeridas pelos nossos missivistas. Q uanto custa obrigar al guém a se classificar como "branco", "negro" ou "pardo" para aumentar ou diminuir suas chances de entrar na universidade ou no serviço público?

U m outro argumento recorrente entre os missivistas é que a desigualdade entre negros e brancos é, sobretudo, uma questão econômica que resulta da falta 
de oportunidades para os pobres em geral. A solução estaria, então, na melhoria do ensino público. Como escreveu, por exemplo, M ário Wilson Ferreira:

[... ] vejo estupefato na edição do Globo de 18/ 4 que uma proposta racista ganha corpo na Comissão de Constituição e J ustiça do Senado e periga transformar-se em lei. Trata-se do estabelecimento de reserva de $20 \%$ de vagas em universidades, Exército e concursos públicos para pessoas negras ou pardas. 0 argumento principal para a criação deste privilégio é que os negros não têm as mesmas condições financeiras que os brancos para estudar e por isto estariam em desvantagem na concorrência por vagas. (O Globo, Cartas dos Leitores, 19 abr. 2002).

$\mathrm{O}$ u, nas palavras de Sérgio de Souza Tôrres: "N ão vejo honestidade intelectual em confundir exclusão social com racismo [... ]. O negro é econômica e, portanto, socialmente marginalizado no Brasil em decorrência da desigualdade de oportunidades após o término da escravidão." (O Globo, Cartas dos L eitores, 21 abr. 2002). E H elena Rumanjek volta a perguntar:

Q ual a diferença entre um negro pobre e um nordestino igual mente desprovido? [...] Por que não reconhecer que a causa real do problema é a má distribuição de renda? Por que não reforçar o ensino fundamental e médio de forma democrática? Essa'é a solução real, ainda que mais difícil. ( 0 Globo, Cartas dos Leitores, 29 ago. 2001)

Enquanto Lílian Borges de Lima insiste:

$\mathrm{N}$ ão é negro que não consegue entrar na faculdade. É o pobre... [o governo] está tentando remendar o problema e não buscar uma solução, como uma reforma no ensino médio e no fundamental de escolas públicas, onde estuda este grande contingente de pobres que não entram nas faculdades. ( 0 Globo, Cartas dos Leitores, 28 ago. 2001)

A opinião desses leitores é familiar a todos os que acompanham o debate sobre a "questão racial" no Brasil. H á quem atribua a desigualdade entre "negros" e "brancos" ao passado escravista e às poucas oportunidades educacionais de qualidade oferecidas para os pobres em geral, entre os quais estão tantos "negros". Q uem se opõe a essa opinião diz que é o preconceito estabelecido após a abolição que é responsável pela reprodução das desigualdades entre "negros" e "brancos". $\mathrm{N}$ a trilha deste debate, José J orge de Carvalho e Rita Segato, antropólogos da U niversidade de Brasília e proponentes de uma política de cotas para "negros" naquela universidade, argumentam que não basta continuar com uma política educacional dirigida apenas para incluir os mais pobres:

De acordo com as projeções do I pea, se a educação brasileira continuar progredindo no mesmo ritmo que hoje, em treze anos os brancos devem alcançar a média de oito anos de estudo e os negros só atingirão essa meta daqui a 32 anos. Portanto, só daqui a três décadas brancos e negros ficariam a par no ensino e concorreriam em pé de igual dade a uma vaga no ensino superior público. Com isso, o Brasil arcaria com o ônus de perder os talentos de mais uma geração de jovens negros, em sua quase totalidade. (C arvalho e Segato, 2002) 
Como vimos, os nossos missivistas, ao contrário de C arval ho e Segato, são mais otimistas quanto a uma solução dirigida à pobreza. $E$ talvez tenham razão. As projeções do IPEA citadas por Carvalho e Segato pressupõem que o sistema educacional siga a mesma dinâmica dos anos passados. M as o sistema não está estável. D ados elaborados pelo I nstituto $N$ acional deE studose PesquisasE ducacionais (Inep) indicam que as políticas públicas dos últimos dez anos produziram mudanças muito radicais no sistema, sobretudo no ensino funda-mental e médio, o que torna simplesmente impossível qualquer projeção mini-mamente confiável.

O s investimentos em pesquisa e em novas políticas para a educação no B rasil na última década produziram uma melhoria sensível no sistema de ensino. A descoberta dos efeitos da repetência e da distorção série/ idade, que consumia as famílias brasileiras e não sensibilizava os formuladores de políticas até bem recentemente, fez a diferença. U ma criança levava onze anos em média para concluir as oito séries do ensino fundamental, e muito poucos concluíam o ensino médio. Fatores demográficos e de políticas públicas mais voltadas para a mel horia do fluxo de estudantes no sistema de ensino fizeram estes números ficarem menos gritantes. H ouve uma quase universalização do acesso ao ensino fundamental e um aumento do número de formandos no ensino básico, o que ampliou as matrículas no ensino médio, que saltaram de 3,770 milhões em 1991 para aproximadamente 8,398 milhões em 2001, (um aumento de mais de 200\%), segundo dados do I nep (M EC/ I nep/ Seec, 2000).

D evido à persistência da repetência, nem todos os que se matriculam se formam. M esmo assim, o número de concluintes triplicou na década de 1990 (MEC/ Inep/ Seec, 2000), passando de 658.725 em 1990 para 1.836.130 em 2000. A grande responsável por esse crescimento foi a rede pública estadual de ensino, que, de 1990 a 2000, aumentou em quatro vezes (400\%) o número de formandos, que passaram de 356.813 em 1990 para 1.390 .815 em 2000 (M EC/ Inep/ Seec, 2000). Enquanto isso, o número de alunos formados nas escolas particulares no mesmo período aumentou de 253.045 para 351.957, ou seja, apenas 39\%. E sses dados indicam que os grandes beneficiários deste aumento são aqueles estudantes que não tiveram acesso à rede privada e que antes estavam excluídos, ou quase, do sistema de ensino.

É de se imaginar que, sendo os mais pobres os grandes beneficiários da expansão do ensino médio público, conforme imaginam os nossos missivistas, tenha aumentado a proporção de brasileiros mais escuros neste nível de ensino. E é isso mesmo que parece estar acontecendo. Segundo os dados do Enem ${ }^{2}$, de 1999 a 2001 a proporção de "negros", "mulatos" e "brancos" passou de 1,9\%, $16,4 \%$ e $76,5 \%$ para 5,3\%, 30,5\% e 58,5\% respectivamente 3 . Esses dados não são conclusivos. M as é difícil não ignorar o que sugerem. Parece mesmo que uma política dirigida a aumentar as o portunidades de todos tem o efeito de aumentar enormemente o número de "negros" e "mulatos" com qualificação mínima para entrar nas universidades. 
No presente momento é impossível saber a proporção de estudantes "negros", "mulatos", "pardos", "brancos" etc. no sistema de ensino superior. Suely Carneiro, diretora do Geledés (I nstituto da M ulher N egra), afirma que

somos oficialmente quarenta e cinco por cento da população do país e apenas dois por cento de nós adentram o ensino universitário. Esse é o patamar de "eqüidade" alcançado, por exemplo, pelas políticas universalistas no campo da educação. (C arneiro, 2002)

Carneiro certamente sabe que, quando fala de "nós", junta os "pretos" com os "pardos", que são as categorias utilizadas pelos recenseadores do IBGE. Q uando fala dos "negros" no ensino superior, porém, pode estar se referindo apenas aos "pretos". Os dados do "provão" 4 apontam para porcentagens dez vezes maiores. M ostram que a proporção de "não brancos" (ou seja, pessoas classificadas como "negras" e "pardas") em relação aos que se classificam como "brancos" varia de um pouco menos de $30 \%$ nos cursos formadores de professores, como matemática (26,6\%), letras (29,4\%), física (28,4\%), biologia ( $26,2 \%)$ e química $(25,0 \%)$, e um pouco mais de $15 \%$ nos cursos profissionalizantes como direito (17\%), odontologia (14,5\%), medicina (18,6\%) e engenharia química $(17,2 \%)$.

A questão, portanto, é se as universidades aumentarão o número de vagas para poder admitir todos os novos postulantes, ou, como é proposto pelos "cotistas", reservarão uma proporção para os "negros" e "pardos". Se optarem pelas cotas, parece que poderão estar favorecendo os "negros" mais bem aquinhoados, como sugere M aria E udóxia de L ima Paes Leme:

Se o objetivo for melhorar as condições sociais dos negros, também será inócua a lei, haja vista que irão preencher as cotas os negros mais bem preparados e de melhor nível econômico, e que não precisam das cotas. Enfim, trata-se apenas de um projeto extremamente demagógico, sem qualquer finalidade social. ( 0 Globo, Cartas dos L eitores, 21 abr. 2002)

Aliás, os nossos missivistas são muito sensíveis às possíveis injustiças sociais que a política de cotas poderá produzir. $M$ ais de um sugeriu que a política de cotas poderá prejudicar sobretudo "brancos pobres". Como diz H élio de Araújo Evangelista:

A cota para negros discrimina o branco mais pobre, pois sem ela poderia alcançar mais facilmente a vaga almejada na universidade ou no emprego público. 0 branco com recursos não terá dificuldades para alcançar seus objetivos. Q uerer superar uma injustiça produzindo outra não parece ser o melhor caminho. (0 Globo, C artas dos Leitores, 24 abr. 2002)

Será que os "cotistas" pensaram mesmo nessas questões? 0 argumento de H élio Evangelista nos comove. A final, a nossa el ite predominantemente "branca" não será em nada abalada por essa política. Q uem sofrerá as conseqüências da legislação são os "brancos" das camadas mais pobres, que serão aqueles a serem excluídos pela reserva de vagas. Será que os legisladores imaginaram a vida social 
do subúrbio carioca, por exemplo, onde pessoas de diversas aparências convivem nas mesmas ruas, escolas, botequins e famílias, compartilhando também a mesma condição socioeconômica? É difícil não concordar com os nossos missivistas quando imaginam um acirramento de tensões raciais neste meio, onde a elite não pisa e conhece apenas de "ouvir dizer".

U m último argumento avançado por alguns leitores é que a instituição de cotas é um ato de paternal ismo que po deria chegar a "humilhar" os beneficiários. Luís H enrique Corrêa de Araújo escreveu:

$\mathrm{N}$ inguém cresce com paternalismo. Essa decisão de separar cotas para cada camada dos chamados discriminados de nada adiantará se não tivermos uma política de respeito a cada um deles. É necessário que eles tenham condições reais de concorrer com todos, pois do contrário farão parte de outra coluna de discriminados: a dosque só conseguiram entrar na administração pública porque tinham um lugar garantido. I sto também é humilhante. ( 0 Globo, Cartas dos Leitores, 15 maio 2002)

$\mathrm{O}$ u, como opinou Carlos Fernandes:

[... ] é uma vergonha que num país como o Brasil se estabeleçam cotas raciais. E stão criando um monstro que até agora não existia no país: o racismo. Amigos negros - um advogado, outro engenheiro - sentem-se humilhados. 0 que deve ser estabelecido são cotas para políticos hipócritas: zero. (0 Globo, Cartas dos L eitores, 12 mar. 2002).

$\mathrm{N}$ este país do favor não surpreende que esses leitores interpretassem as cotas como mais uma dádiva desenhada para fortalecer os políticos às custas de um eleitorado submisso e humilde.

Pode ser. M as o que realmente pudemos constatar é que os eventos que descrevemos, e a morna reação da sociedade como um todo, indicam que 0 poder discricionário do presidente e de seus ministros é muitíssimo grande nessa democracia. M udar o rumo da política racial do a-racismo e do anti-racismo e a celebração da hibridez para o reconhecimento de apenas duas "raças" a serem oficialmente admitidas na distribuição de bens e serviços públicos, ou seja, mudar a armadura da ideologia racial nacional sem debate nem votação, poderia ter interessado a nossos cientistas políticos. M as os políticos em geral e a grande maioria dos cientistas políticos mantiveram um silêncio notável sobre esse assunto. Por quê?

Várias respostas (não mutuamente exclusivas) nos vêm à mente. U ns podem não atribuir importância alguma à introdução de cotas, o que implica que eles consideram insignificante essa ruptura com os princípios formais do constitucionalismo liberal. O utros podem temer entrar num campo no qual, ao criticarem as medidas, podem facilmente ser eles próprios acusados de racistas, ou "antinegros". O utros podem se sentir um pouco anacrônicos ao se opor às políticas de identidade tão em moda no mundo globalizado e pós-Guerra Fria, temendo ser identificados com os velhos comunistas, que sempre negaram qualquer 
especificidade fora da luta de classes. 0 utros ainda podem acreditar que as medidas tomadas não terão tanto impacto assim e que tudo não passa de um grande esforço para impressionar os ingleses! E não pensamos nos ingleses apenas figurativamente. $\mathrm{N}$ ão duvidamos que os governantes, ao poderem se levantar em arenas no exterior, como na C onferência de D urban, para mostrar o quanto se faz para dirimir as desigualdades raciais no Brasil, impressionem as agências e a comunidade internacionais.

Por que estamos correndo o risco com este ensaio de chamar a ira dos militantes negros, colocando em dúvida a propriedade de cotas raciais no Brasil, sobretudo dado o fato de que há muitos anos conhecemos e temos discutido 0 grau do racismo à brasileira e a extensão das desigual dades raciais?

Em primeiro lugar não estamos convencidos de que seja possível "corrigir" séculos de desigualdade de qualquer ordem, racial ou não, por meio de uma política de custo zero. A final, a política de cotas não tem custo material algum. O s nossos "nativos" indicaram muitos custos de outra ordem. 0 argumento de que as cotas acabarão incentivando animosidades "raciais" não pode ser facilmente descartado, porque a sua lógica é cristalina. $\mathrm{N}$ ão se vence o racismo celebrando 0 conceito "raça", sem o qual, evidentemente, o racismo não pode existir. I niciativas de ação afirmativa oriundas da sociedade civil produzem conseqüências semelhantes para aquelas poucas pessoas envolvidas. $M$ as quando cotas raciais se tornam política de E stado, determinando a distribuição de bens e serviços públicos, ninguém escapa à obrigação de se submeter à classificação racial bipolar. 0 impacto sobre a sociedade como um todo não pode ser subestimado, portanto.

E m segundo lugar, como tentamos demonstrar, nada nos convence que a solução "universalista" foi, de fato, esgotada. Em terceiro lugar, imaginávamos que os nossos governantes pudessem ter tido um pouco mais de cuidado antes de abandonar um projeto nacional pautado no não racismo. Por que não aprofundar e expandir políticas racialmente não neutras ${ }^{5}$ como as que foram adotadas no que se refere à repetência e à distorção série/ idade no lugar da racialização que as cotas impõem? Colocar, por exemplo, uma escola pública de melhor qualidade numa periferia de uma grande metrópole, em vez de instalar a mesma escola num bairro de classe média alta, obviamente propiciaria mais oportunidade para os negros (posto que os pobres são majoritariamente negros) do que para os brancos. M as uma política dessas teria custos materiais enormes, e seria muito difícil, se não impossível, convencer as classes médias afetadas a aceitar tamanho sacrifício. Para aqueles que perderiam com políticas de transferência de recursos, é mais fácil apoiar cotas que não os afetam e tampouco custam absolutamente nada. Redenção de graça!

O novo reitor da U niversidade Federal do Rio de Janeiro, C arlos Lessa, não acredita na eficácia de cotas raciais e prefere investir na permanência de alunos pobres na universidade criando programas de bolsas para os estudantes mais pobres. De novo uma política racialmente não neutra, mas também não 
racializadora. A posição de Carlos Lessa se opõe diametralmente ao projeto de lei atualmente em discussão no Senado da autoria do senador J osé Sarney, que prevê cotas de vinte por cento para negros e pardos em todas as instituições públicas e privadas do ensino superior. A posição do reitor da UFRJ também coloca o dedo numa das feridas da universidade pública que poucos querem ver ou sanar: de cada cem alunos que entram apenas cinqüenta saem formados! Q uem sabe se a invisibilidade deste fenômeno tem algo a ver com a velha lógica da exclusão? É nossa esperança que a intenção do reitor da U FRJ em encontrar caminhos que não racializem a universidade e a sociedade acenda um debate público que, como mostramos, tem sido realizado por poucas pessoas e tem tido pouca densidade até o momento. Afinal, a questão racial não é assunto apenas dos brasileiros que se definem como negros; jaz, pensamos, no epicentro da sociedade nacional de tal forma que as decisões tomadas ago ra, mesmo se tiverem pouco efeito no presente imediato, certamente definirão os contornos do Brasil do futuro.

\section{N otas}

1 A pesar de o governo e das agências de fomento internacionais terem gastado fábulas na divulgação das informações sobre a Conferência de Durban, não conseguimos descobrir até hoje a composição deste comitê.

20 Enem (Exame $\mathrm{N}$ acional de $E$ nsino $M$ édio) é realizado anualmente pelo $M$ inistério da Educação. $O$ exame não é obrigatório e, a partir do ano 2000, passou a ser gratuito. Podem se submeter a ele todos as pessoas que concluíram o ensino médio, não só os que finalizaram este nível de ensino no ano do exame, mas também aqueles que o concluíram em anos anteriores. 0 Enem vem sendo utilizado por algumas instituições de ensino superior como critério de seleção de candidatos aos cursos superiores. Os candidatos ao Enem respondem um questionário socioeconômico que tem fornecido dados importantes sobre as características dessa parcela ainda reduzida dos que finalizam o ensino médio no país.

3 O Enem utiliza uma taxonomia"racial" sui generis, com três categorias, "negro", "mulato" e "branco", que é uma versão, digamos, mais vernacular da centenária taxonomia do IBGE, que utiliza as categorias "pretos", "pardos" e "brancos".

4 Provão é o nome popular que passou a denominar o Exame $\mathrm{N}$ acional de Cursos aplicado anualmente aos concluintes de um conjunto de cursos de graduação do país. Em 2000, foram examinados formandos de dezoito cursos universitários em todo o país. Ao contrário do Enem, este é um exame obrigatório, mas ainda não é aplicado a todos os cursos de graduação existentes. O s candidatos a este exame também respondem a um questionário socioeconômico, que tem revelado o perfil dos concluintes das carreiras universitárias abrangidas até o presente.

5 Por políticas racial mente não neutras entendemos aquelas que, dirigidas a determinadas áreas de pobreza, automaticamente atingem grande número de negros. Este conceito foi desenvolvido por Bowen e Bok (2000). 


\section{Referências bibliográficas}

AGIER, Michel. Dossier pour un numéro thématique des Cahiers du Brésil Contemporain, Paris, 2002 (mimeo.).

BOK, D. eBO WEN, W. G. Shape of the R iver: L ong-term C onsequences of C onsidering Race in College and U niversity Admissions. Princeton, Princeton U niversity Press, 2000.

CARNEIRO, S. "I deologia tortuosa". CarosA migos. São Paulo, vol. 64, jul. 2002. Site Caros Amigos, acesso em 20 out. 2002.

CARVALH O, J osé J orge de e SEGATO, Rita. Cotas para estudantes negros no Brasil. siteFórum deAntropologia do/ no Brasil. Disponível em: «ttp:/ / listhost.uchicago.edu/ mailman/ listinfo/ ant-br>, acesso em 24 jul. 2002.

FRY, Peter. "Politics, $\mathrm{N}$ ationality and the $\mathrm{M}$ eanings of Race in Brazil". D aedalus, vol. 129, n. 2, 2000, pp. 83-118.

HENRIQUES, Ricardo. "É preciso tratar desigualmente os desiguais". O Globo, Rio de Janeiro, 21 abr. 2002. Entrevista feita por $\mathrm{H}$ elena Celestino e M aiá M eneses. Site $\mathrm{O}$ Globo, acesso em 24 jul. 2002.

INEP/ MEC/ SEEC. Censo Escolar 2000. Brasília, 2000.

INEP/ MEC.‘EN EM : relatório pedagógico 1999. Brasília, 1999.

INEP/ MEC. EN EM : relatório pedagógico 2000. Braślia, 2000.

INEP/ MEC. EN EM : relatório pedagógico 1999. Brasília, 2001.

INEP/ MEC. Exame N acional deCursos. síntese do Provão 1999. Braślia, 1999.

MAGGIE, Y. M edo do feitiço: relações entre magia e poder no Brasil. Rio de Janeiro, M inistério da Justiça, 1992.

O GLOBO. E dições diversas (seção C artas dos L eitores). Rio de Janeiro, 2001-2002.

RIO DE JANEIRO (Estado). Lei no 3.708, de 9 nov. 2001. Portal Interlegis, acesso em 20 out. 2002

Programa $\mathrm{N}$ acional dedireitos $\mathrm{H}$ umanos 1996, Biblioteca $\mathrm{V}$ irtual de $\mathrm{D}$ ireitos $\mathrm{H}$ umanos, U niversidade de São Paulo, D ireitos H umanos no Brasil, acesso em 20 out. 2002.

SO UZA, J. "M ulticulturalismo e racismo: uma comparação Brasil-Estados U nidos". Paralelo 15, Brasília, 1997, pp. 23-35.

THOM AS, K. "The Political Economy of Recognition: Affirmative Action Discourse and Constitutional Equality in Germany and the USA". The Columbia Journal of European Law, vol. 5, n. 2, 1999, pp. 329-364.

Resumo - o governo do Estado do Rio de Janeiro, depois de votada por aclamação na Assembléia L egislativa, adotou em 2001 uma política de cotas para "negros e pardos" nas suas instituições de ensino superior. $\mathrm{Na}$ trilha da preparação da III Conferência M undial das $\mathrm{N}$ ações U nidas de Combate ao Racismo, D iscriminação Racial, Xenofobia 
e Intolerância Correlata que teve lugar em Durban, na África do Sul, em 2001, esta política e aquelas decretadas pelo governo federal não foram objeto de um amplo debate público. Este debate começa agora fracamente depois dos fatos consumados. O sautores analisam os caminhos dessa mudança de rumo radical do paradigma racial brasileiro através da descrição de cartas de leitores ao jornalO Globo. Estes leitores, os nossos "nativos", são ponto de partida para avaliar as dificuldades e as conseqüências que uma tal política de Estado impõe à população brasileira, especialmente àqueles que, longe do poder das elites, serão obrigados a se definir "racialmente" para serem tratados desigualmente na luta por vagas no serviço público e na universidade.

A вsтract - IN 2001, a law obliging the institutions of higher learning of the State of Rio de Janeiro to reserve $40 \%$ of all places for "blacks and browns" was passed by acclamation and without debate. Along the path of the preparations for the III U nited $\mathrm{N}$ ations World Conference against Racism, which was held in Durban in 2001, this policy and other similar ones decreed by the federal government came into being without ample public debate. Ex post facto this debate is now only beginning. The authors analyze the sequence of this radical change in Brazil's racial paradigm through a description of readers' letters published in the newspaper 0 Globo. These readers, our "natives" lead us to evaluate the difficulties and the consequences that this government policy imposes on the Brazilian population, especially those poorer citizens, who, far from the power elites, will now be obliged to define themselves "racially" in order to be treated unequally in the battle for places in the civil service and public universities.

Y vonneM aggie e Peter Fry são professores de Antropologia do Instituto de Filosofia e Ciências Sociais da U niversidade Federal do Rio de J aneiro (U FRJ).

Texto recebido e aceito para publicação em 4 de dezembro de 2003. 